\title{
GOZOS, DIFICULTADES Y APOYOS EN EL TRANSCURSO DE LA VIDA MATRIMONIAL
}

DOI: https://doi.org/10.52039/seminarios.v60i212.200

FERNANDO HERRERA Y CRISTINA ZAFORAs*

\section{ACtUALIDAD DE LA FAMILIA POR EL SínOdO DE LOS OBISPOS}

Dada la gran actualidad, por lo menos en algunos ámbitos, del Sínodo de los Obispos, del que se acaba de celebrar la III Asamblea General Extraordinaria, consideramos que puede ser oportuno en estas breves líneas, y para concretar ideas en torno al tema que nos ocupa, perfilar desde nuestra perspectiva algunos puntos del esquema de los capítulos I y II de la segunda parte del denominado Instrumentum laboris de la citada Asamblea.

Planteada la posibilidad de escribir algo sobre la vida matrimonial, a la luz de las próximas asambleas del Sínodo sobre la familia convocadas por el Papa Francisco, nos preguntamos, mi mujer y yo, que en esto vamos juntos, por qué podrían resultar de interés algunas ideas y experiencias para la labor pastoral o para el enriquecimiento personal de sacerdotes, seminaristas u otros matrimonios.

Tratando de dar respuesta a ello entendemos que la perspectiva más adecuada, y a nuestro alcance, es la de presentar la realidad de la vida matrimonial del entorno próximo que nos rodea; la realidad universal es muy vasta, aunque con numerosos elementos comunes, como muestra el Instrumentum laboris. Esta realidad es poliédrica y presenta por tanto múltiples posibles acercamientos; sería interminable la sola enumeración de los mismos.

Por ello y, extrayendo algunas de las ideas vertidas en ese documento de trabajo del Sínodo, nos fijaremos en algunos de los puntos señalados en los citados capítulos 1 y 2 de su segunda parte.

\section{MEJORAR LA PREPARACIÓN PARA EVITAR LAS RUPTURAS}

Habida cuenta de que la preparación al matrimonio (y en concreto al matrimonio cristiano), como señala el Directorio de Pastoral Familiar en España, no es tarea de un momento ni de un tiempo concreto sino de toda la vida desde que

* Fernando Herrera y Cristina Zaforas son matrimonio. Fernando dirige la Subcomisión de familia de la Conferencia Episcopal Española. Cristina es directora de la Asociación Persona y Familia, del Instituto Juan Pablo II. 
nacemos, y particularmente desde que nacemos a la vida de fe, en el bautismo, es importante resaltar la importancia de la preparación a lo largo de las 3 fases que señala el directorio sin olvidar esa preparación remota que realizan, o deberían realizar, los padres desde el inicio de la vida de sus hijos.

Dicha preparación se ha de basar en los tres pilares que son:

-la frecuencia de la oración, oración en familia que lleve a la oración individual y/o en la parroquia;

-la frecuencia de los sacramentos, incluida la Eucaristía familiar;

- una vida de los padres en familia que testimonie una fe auténtica. Esta autenticidad en la vida familiar, en la transmisión de la fe, resulta esencial que sea una fe viva, testimonial y alegre, traspasada por la esperanza y la caridad. Sin estos elementos, la persona en general, y el niño en particular, difícilmente llegará a experimentar y a hacer suyo que el mensaje que le comunican en su hogar y en la vivencia de la parroquia encierra una verdad auténtica. A lo sumo podrá llevarle a repetir frases vacías, comportamientos miméticos que acepta sin comprender y sin hacerlos vida personal; no le llevará a vivir con alegría, sobre todo cuando otros mensajes de distinto signo lleguen a sus oídos, a sus corazones, que terminarán por anular la experiencia de la causa profunda y vital de dicha alegría.

En esta forma de convivencia, natural y conforme a la naturaleza de la persona, llena, en general, de gozos y satisfacciones pero no exenta de momentos de dificultad, de caídas y de errores, la misión de los padres es insustituible ya que ellos son los primeros transmisores de la fe y los custodios del crecimiento de la vida recibida en el bautismo. Los padres participan de la autoridad y del amor de Dios Padre y del Cristo Pastor recibiendo del Espíritu Santo los dones que necesitan para el crecimiento humano y cristiano de sus hijos ${ }^{1}$.

Esta misión la realizan los padres iluminando los acontecimientos de la vida familiar con la fe, la oración y la celebración de los eventos, y con una colaboración activa en la formación religiosa que sus hijos reciben en la parroquia o en los colegios. «En la catequesis y todo el proceso de educación en la fe es esencial la cooperación de los padres para que exista una verdadera transmisión de la iniciación cristiana de la fe»².

En este tiempo que denominamos preparación remota el apoyo, y la colaboración de los padres con la Iglesia en el ámbito parroquial es de vital importancia $y$, a menudo, no debe esperar el párroco a que los padres lleven a los niños a la parroquia, pues ya ni el bautismo ni el «atractivo» de la fiesta de la Primera Comunión, suponen las, a veces dudosas, pero al fin y al cabo motivaciones, para que las familias se acerquen a la parroquia.

1. Cf. Juan Pablo II, Familiaris consortio 38.

2. Conferencia Episcopal Española, Directorio de la pastoral familiar de la Iglesia en España, 183. 
Ahora cada vez más van teniendo los párrocos que salir a las «periferias» de la comunidad y a las de las propias personas que han ido, por razones diversas, quedando o quedándose marginadas respecto de la referencia de un Dios Padre que en la Iglesia sigue presente.

La parroquia puede y debe prestar una ayuda a las familias. En los años de infancia y juventud de los hijos puede darse ofreciendo «Escuelas de Padres» a las que acudirán con cierta «facilidad»; en ellas encuentran un ámbito próximo geográficamente, económicamente asumible si así se procura, viendo en ellos una ayuda ante dificultades comunes para las que no se sienten preparados. En dichas escuelas se pueden introducir elementos religiosos de forma natural.

A medida que los jóvenes van creciendo se impone una adecuación en la formación y preparación para la vida en general y para el desarrollo de la Vocación al Amor concretando el estado de vida al que sea llamado cada uno. Es importante entonces transmitir y dar a conocer la complementariedad de las dos formas de responder a la vocación al amor que son la de la vida consagrada y la vida conyugal.

Para el adecuado discernimiento del estado de vida al que son llamados los jóvenes, será un elemento importante, al que se les debe invitar, la dirección espiritual inmersa en las diversas actividades de los grupos de jóvenes, parroquiales o de movimientos con carismas concretos que colaboren de forma integrada con la vida parroquial. En estos grupos de jóvenes se ha de dar la continuidad en la vida de la Iglesia que a menudo se interrumpe tras la recepción de la «Primera Comunión». Es necesaria la formación de sujetos cristianos, evitando el puro activismo o la priorización de las «actividades» -puramente lúdicas con frecuencia-sobre la vida espiritual -vigilias, eucaristías, celebraciones penitenciales, retiros espirituales- que en ocasiones se han reducido, y a veces evitado, por una errónea idea de que con ello se atraía a los jóvenes o impedía su alejamiento.

En el tiempo más inmediato a la preparación al matrimonio, que resulta igualmente fundamental para llevar a buen puerto esta difícil empresa, nos encontramos con los denominados «cursillos prematrimoniales» cuya eficacia se podría pensar que, en muchos casos, es escasa o nula para conseguir la preparación necesaria. Lógicamente no es posible pedirles un mínimo de eficacia en este sentido sin una trayectoria -itinerario de fe- necesaria para conseguir un mínimo de preparación real y formación del sujeto cristiano que pueda constituir un matrimonio y por ende una familia cristiana. En los citados cursillos u otras ocasiones, testimonios de matrimonios que han sido y son capaces de afrontar y salir adelante ante las dificultades, celebraciones de bodas de plata, u oro, públicas y relevantes, en las agendas parroquiales deberán ser fomentadas por los sacerdotes en sus parroquias.

Con ello se podrá colaborar a mostrar la belleza tantas veces oculta o ensombrecida por las frecuentes separaciones y divorcios. 


\section{Algunas sugerencias pastorales}

En las parroquias sería de agradecer que los sacerdotes, formados en la medida de sus posibilidades, procuren ayudar a los matrimonios y las familias, especialmente a los matrimonios jóvenes, conscientes de que en los cinco primeros años, ante las nuevas y difíciles situaciones que afrontan los recién casados y en muchos casos «nuevos padres», se produce un gran número de rupturas. Una ayuda especializada que la Iglesia puede prestar, y de hecho presta, es la de los Centros de Orientación Familiar que, donde existen, deberían ser dados a conocer en mayor medida así como fomentar la colaboración entre ellos.

En el origen de estas rupturas se podrían apuntar causas sociológicas, macroeconómicas, laborales, ideológicas, antropológicas -emotivismo, relativismo, falso concepto de la libertad, ideología de género, crisis económicas- que sin negarlas ni minimizarlas deben dar paso en primera instancia, en la labor pastoral, a aspectos cotidianos en los que ayudar a los matrimonios y sus familias.

Entre estos aspectos de la relación de pareja, uno muy significativo es el de las dificultades de comunicación. Estas dificultades a nivel humano parten, a mi entender, de razones diversas pero de manera importante de una corriente de pensamiento por la que se ha procurado en los centros escolares, en la familia, que la persona sea considerada como un individuo que debe aspirar a tener la mayor autonomía posible, para así tener la mayor independencia; de este modo se sugiere que esta autonomía la tenga la mujer frente al marido y el hijo frente a sus padres. De esta forma se conduce a un aislamiento sin sentido de la persona que entra en colisión con el hecho de que el hombre es un ser social llamado a la comunión y de forma particular a la comunión familiar.

Podría decirse también que subyace, a menudo, un ateísmo práctico en esta actitud, incluso de algunos que, siendo religiosos y practicantes, se pueden quedar en los ritos sin profundizar en el sentido de la fe, de la vida y ello alcanza a sus relaciones con la familia, los hijos.

El ambiente nos impregna de un modo de pensar, de vivir y de sentir de la que a veces no somos conscientes pero que nos debe de hacer revisar nuestra propia conciencia, nuestro cómo «creer en el amor».

Son de gran ayuda, y conviene favorecerlo, las prácticas que formalizan algunos movimientos como los Equipos de Nuestra Señora en la llamada «sentada» que consiste en sugerir que los matrimonios acuerden, al menos una vez al mes, un tiempo para establecer un espacio de comunicación y diálogo en presencia de Dios con el objeto de que, en un clima de oración y de cordialidad, compartan cuestiones delicadas, que pueden ser sencillas, pero que, en todo caso, se pueden aclarar en esa comunicación.

Por tanto, una receta sencilla y esencial es que se fomente el compartir actividades entre los cónyuges y con la familia, incluidas actividades religiosas, como convivencias o celebraciones en los grupos parroquiales. 
En algunos casos se puede tener que acudir a especialistas para superar dificultades de comunicación, derivadas de patologías surgidas por la historia en las familias de origen o por la propia naturaleza de la persona con déficits o dificultades sociales especiales; pero en la mayoría de los casos se proveerá de una ayuda muy eficaz alentando y favoreciendo la comunicación desde el perdón, el agradecimiento y recuperando las palabras amables; según la trilogía que recordaba el Papa Francisco del «gracias, perdón y por favor» son gestos que favorecen el restablecimiento de la comunicación en la pareja y con ello recuperar la armonía y la concordia familiar.

En este sentido es importante recordar que los niños no viven tanto del amor que les tienen los padres, cuanto del amor que se tienen los padres entre sí y del que emana el amor a sus hijos. En este sentido es tan importante evitar el «padre ausente» como la madre súper-protectora y omnipresente que ahogue la figura de un padre que pierde su identidad.

Ante esta problemática de dificultad en la comunicación se podría caer en el error de la demonización de las tecnologías y los medios de comunicación por dos razones que aparentemente pueden hacerlos considerar perniciosos. De un lado parecen fomentar el aislamiento de las personas o el alejamiento de los miembros de la familia. Convendría analizar las distintas situaciones y ver en qué medida dichos medios procuran o favorecen dichas situaciones o si ponen en evidencia el alejamiento previo debiendo actuar sobre las causas de esos alejamientos antes que renegar de los mismos. Por otro lado, hoy no parece cuestionable que el uso obsesivo de dichas tecnologías encierra riesgos evidentes y constatados, que van desde las posibles adicciones o peligros de acoso a información inapropiada o incorrecta.

En todo caso conviene conocer el uso de los medios y los riesgos que suponen, máxime cuando las nuevas generaciones pueden estar siendo víctimas de unos medios que, como sucedió cuando irrumpieron otras tecnologías, pero de forma más rápida y profunda, va superando a las generaciones de los adultos.

A los riesgos citados se ha de añadir el problema de la dificultad de conciliar la vida familiar y laboral, lo cual en muchos casos lleva a que los padres no dispongan del tiempo mínimamente necesario para acompañar y supervisar la vida en general y el uso de estos medios en concreto con los peligros que encierran y ante los cuales se ven incapaces de ponerse al día.

\section{CONCLUSIÓN}

-Aunque quizás es más crítica la situación de ausencia de personas con voluntad de establecer compromisos matrimoniales, ya sea civiles o religiosos, ante las dramáticas situaciones de las, cada vez más numerosas, rupturas matrimoniales es importante revisar y mejorar la preparación al matrimonio para favorecer que estos tengan vocación de eternidad durante toda la vida de los cónyuges. 
-También es muy importante la ayuda y colaboración que pueden prestar los Centros de Orientación Familiar, sacerdotes y laicos formados en temas de Matrimonio y Familia (en instituciones como el Instituto Juan Pablo II).

-Aunque lo esencial de las necesidades de comunicación y expresiones de afecto entre los cónyuges es y serán siempre comunes a todas las generaciones, algunos medios y tecnologías propias de los tiempos han de ser consideradas y conocidas, teniendo en cuenta por un lado los peligros de las mismas y por otro que lo esencial está en el corazón de las personas y su deseo de Dios del que se deriva la «vocación al amor» de todo hombre. 